\title{
On the Optimization of Specialty Structure in Universities Based on Professional Evaluation
}

\author{
Hua-liang LU ${ }^{1}$, Qiu-yu YE ${ }^{1}$ and Cheng ZHANG ${ }^{2, *}$ \\ ${ }^{1}$ School of Business Administration, Nanjing University of Finance and Economics, Nanjing, China \\ ${ }^{2}$ School of Economics, Nanjing University of Finance and Economics, Nanjing, China \\ ${ }^{*}$ Corresponding author
}

Keywords: Specialty Evaluation; Colleges and Universities; Specialty Structure.

\begin{abstract}
The essence of higher education is specialty education, so the specialties and majors should be put emphasis on in education and teaching in colleges and universities. In fact, the evaluation of colleges, universities and specialties has become the important gauge for understanding the development of higher education, and an important means to improve the quality of higher education. Therefore, it is imperative to attach importance to specialty evaluation and analyze specialty structure and the regularities in its adjustment, so as to promote the adjustment and optimization of the specialty structure in colleges and universities. It not only helps to enrich the research of relevant theories, but also is of great significance to the reform of higher education in China.
\end{abstract}

\section{Introduction}

In the part of "Constructing Modern University System" in "National Middle and Long-term Educational Reform and Development Plan (2010-2020)" ("Plan" for short), it was emphasized that "We should promote specialty evaluation, encourage specialized agencies and social intermediaries to evaluate the level and quality of disciplines, majors and courses in universities." [1] The "Plan" regards specialty evaluation as an important measure for our higher education to build a modern university system in the future, and it embodies the fundamental position in the development of higher education in China.

Generally speaking, specialty evaluation is the assessment of the quality of teaching in colleges and universities, or the estimate of certain major, college, department and school. It concerns that the evaluation subjects estimate the plan of talent training, the quality of the learner educated accordingly as well as the prerequisites that bring about and ensure the quality of the talents, according to the subjects' needs and the proposed evaluation implementation scheme and value judgment standard (specialty evaluation index system). It aims at making the prerequisites be suited to the requirements of the development of social economics.

Professional structure refers to the internal combination, categories and proportions of the majors set up by colleges and universities according to their own running conditions and national policies as well as regulations. It is directly related to the specifications and quality of the training of talents in colleges and universities, as well as "the relationship between the institutions of higher education and the government, as well as the combination of the training of higher education and the needs of the society". Theoretically speaking, as the organizational form of the curriculum, the professional setting should meet the needs of the special talents in various fields and posts. Therefore, with the rapid development of science and technology, the upgrading of the industrial structure and the change of social life style, the professional structure of colleges and universities will be in the process of dynamic adjustment. There will be no perfect and static balance between them. It is required to be constantly adjusted and optimized through professional evaluation to pursue a more reasonable and professional structure with the times [2]. Therefore, how to speed up the adjustment of the structure of disciplines and specialties according to professional evaluation, to construct a scientific and sane system, and to cultivate specialized talents with high quality adapted to the demands of economic and social development has become the urgent task of higher education in the 
new century.

\section{Theoretical Framework}

\subsection{Researches on Professional Evaluation}

The traditional methods of university professional evaluation include the method of information resource utilization, relative difference evaluation, intra-individual differences evaluation, quantitative method (Bibliometrics, Analytic Hierarchy Process), non-quantitative method (grade evaluation method, self-organization theory). Among them, the information resource utilization method of the university professional evaluation can realize the full mining of the evaluation information and data; the relative difference method and the intra-individual differences evaluation mainly refer to the concrete thought that permeates the evaluation; the Bibliometrics is to measure the professional scientific research level; the rank method in the non-quantitative method is the thought of evaluation; self-organization theory is a classical strategic thought of professional evaluation in universities [3]. This paper largely adopted Analytic Hierarchy Process (AHP) with the combination of subjective and objective methods when setting index weights. While subjectively setting the relative importance, the author consulted the previous index weights of professional evaluation and various scientific proofs; when objectively measuring and calculating, the author compiled weight calculation program of AHP, it means that only more than two dimensions of the matrix should be input in the calculation, which largely enforced the accuracy and rapidity.

\subsection{Literature review on the Optimization of Professional Structure}

Bao (2007) proposed that the professional setting should follow the adaptability principles adapted to the needs of local economic and social development, the priority development principles that put emphasis on distinguished features and connotation, the principle of sustainable development in coordination with the discipline construction and the principle of harmonious development with attention to both scale and benefit, and the development of local economy and culture to the talents. The demand is the primary basis. What's more, we should regard the demands of the local economic and cultural development as primary basis, the development orientation and the advantages of universities as necessary basis, the situation of the existed teaching resources as basic basis, and national and provincial authorities' requirements for specialty setting as main basis [4]. According to Zhao (2007), specialties should set up by following the principles of scientificity, development, feasibility, adaptability and efficiency. Ma and Jia thought that the optimization of professional structure should be based on social and economic development, especially the development of local colleges and universities, which should be complementary to the level of local economic development, and be reflected in the layout of colleges and universities and the orientation of running schools [5]. Xu (2006) pointed out such existing problems in the optimization of professional structure as the lack of market characteristics, the over-rapid expansion of scale, the graveness of convergence phenomenon, over-emphasis on connotation while belittling denotation and emphasis on tradition while belittling the emerging, etc., and she suggested that the optimization of specialty structure should be based on social demands, be guided by market supply and demand, focus on the adjustment of the stock structure, broaden the connotation, promote the cross and integration of specialties, strengthen the macro management of the government and improve evaluation system, etc. [6] For Dong (2011) pointed out that the specialty structure in Chinese universities and colleges did not cohere with economic development and changes, the subjects were separated from the society, and the features were weakened because of the extremely pursuing quantity and the quality problems caused by blind adjustment, etc., and Dong also proposed the corresponding suggestions. 


\section{The Importance of Optimizing the Professional Structure of Colleges and Universities in China}

\subsection{The optimization of specialty structure is the inherent requirement of economic structural adjustment}

The optimization of discipline structure and the adjustment of talent structure have always been closely related to economic and social development. Nowadays, the adjustment and optimization of the economic structure has become the general trend of the world and both developing countries and developed countries are trying to grasp the rare historic opportunity of the new round of economic structural adjustment and industrial upgrading which are inseparable from the support of education. The more advanced and globalized the economy is, the more important and prominent the educational, scientific research and laborers' qualities are [8]. That's to say, in order to keep in pace with the adjustment of economic structure, it is necessary that the education adjusts itself at the same time, and the optimization of the subject structure is one of the adjustments.

\subsection{The rapid development of worldwide science and technology urgently needs the adaption of discipline and professional}

In the twenty-first Century, the trend of highly differentiation and highly integration between science and technology is becoming more and more obvious. The high degree of differentiation is embodied in the expansion of the subject scale, the sharply increase in the quantity, whereas the combination embodies in the infiltrating among the subjects [9]. The above two trends will inevitably result in the emergence of new disciplines and new specialties, and these trends put forward new requirements for the optimization of the structure of disciplines and the training of talents in colleges and universities. Moreover, it is required for higher education institutions to carry out the reorganization of disciplines and specialties so as to meet the practical needs of the development of social and economic construction.

\subsection{The popularization of higher education urgently needs the adaptation of discipline and professional structure}

At present, our country is in the key stage of building a well-off society in an all-round way and building a socialist harmonious society. It is more urgent than ever before to cultivate multi-disciplinary and professional talents. However, the structure of the discipline of higher education cannot meet the needs of the society. Therefore, colleges and universities must seize the great opportunity to expand enrollment, combine the optimization of subject structure with the long-term development of the school, adhere to the scientific outlook on development as guidance, speed up the optimization of subject specialty, and promote the coordinated development of scale, structure, quality and benefit [10]. At the same time, with the advent of the era of popularization of higher education and the demand for the diversification of talents, the scientific orientation of colleges and universities is urgently required to develop their own features and promote education quality so as to cultivate the talents needed by the society. The key to the scientific orientation is that the optimization of the discipline structure should be in accordance with the orientation of the school. Therefore, it is important to speed up the optimization of the specialty structure so as to solve the problem of structural maladjustment which is not only for the demand but also in short supply at present.

\section{Problems Existing in the Optimization of Professional Structure in Chinese Universities}

\subsection{Lack of market characteristics in the setup of specialty, difficulty in adaption of specialty structure to social economic development}

By the lack of market characteristics, we mean that the specialties are not set up for market and they can't meet the needs of market for various talents. Although the discipline structure has been constantly adjusted in recent years, the structure of professional structure suited to the adjustment of industrial structure has not been completed, and it also fails to meet the new demands of the 
upgrading of industrial structure and the change of the structure after the entry of WTO to the training of higher quality talents. It leads to the situation of demand and supply characterized by total surplus and structural deficiency, followed by which is the shortage of high and new technology talents and high-level management talents urgently needed in the development of the country. What's more, the stock of applied talents for local and regional economic construction is relatively less, and the professional proportion that closely related to social and economic development is relatively low. The economic structure, the industrial structure and the discipline structure of colleges and universities are dialectically and closely connected. They jointly promote the adjustment, transformation and upgrading of economic and industrial structure, and it is required to adjust the discipline structure of higher education to be accordant with the economic development [11]. In addition, colleges and universities should put the needs of social and economic development in an important position so as to cultivate various talents who can adapt themselves to the society and can make contributions to the social development. In this way, the professional structure and level are compatible with the social and economic structure.

\subsection{Go in for grandiose projects and expand the specialty at high speed}

After the adjustment of the subject catalogue in colleges and universities in 1998, the professional types have been compressed to 249 types, and the professional scale has been controlled. However, the number of majors in colleges and universities is still expanding. Especially after the expansion of enrollment, some colleges and universities have gradually developed from the original single-disciplinary institutions to multi-disciplinary or comprehensive direction, and the scale of disciplines and specialties has been expanding [12]. In addition, a number of new regional colleges and universities have been expanding the running scale, and some universities have more than 10 undergraduate majors in one year, which makes the number of colleges and universities expand rapidly.

\subsection{Inadequate examination and approval and lack of preparation}

In recent years, the high growth rate of some hot or rare majors, such as IT $(70.01 \%)$, bioscience $(75.97 \%)$ or related specialties, aggravates the deficiencies in teachers, equipment, sites and rooms, followed by the unguaranteed quality of teaching and low quality of the talents.

\section{The Basic Countermeasures to Optimize the Professional Structure of China's Colleges and Universities}

\subsection{To highlight social value orientation and optimize the professional structure guided by market demand}

Nowadays, higher education is not humanistic education, which must serve the society and economy to cultivate capable talents. The situation calls us for setting up courses and specialties by emphasizing the orientation based on the needs of society so as to train applied talents.

To optimize the professional structure based on market demand is to set up majors geared to the needs of locality, set up according to market and related to industry. In fact, the development of regional economy and market demand are the supporting points of the subjects and specialties, so the needs of regional economic industrial structure adjustment and upgrading should be closely combined while making curriculum and setting up majors. Then universities and colleges must carry out self-positioning, self-planning to realize the linking up with local economy and market [13]. They should strengthen the connection with the industry and enterprise, set up the committee that the experts participate to offer professional guidance, and work out the training target and curriculum catering for enterprise and industry. Only in this way can a mutually beneficial and virtuous circulation school running mechanism be set up.

When it comes to the market demand oriented optimization of professional structure, we mean that we should establish a flexible education, grasp the impact of the talent market on the professional structure and layout, and coordinate the contradictions between the plan and the market. 
The demand for talent market is varied, so it is required that in higher education we diversify personnel training and make out the needs of the market and the requirements of the specifications of professional talents. Probing into various training mode such as "Sandwich" mode and "Order-based" mode, actively promoting interaction and cooperation between universities and enterprises, letting enterprises participate in the process of teaching, the higher education can help realize resource sharing, advantage complementation and guarantee the quality of applied talents.

By market-oriented optimization of specialty structure, we mean that we can set up new majors in advance in a moderate way. It is because that the period of university personnel training is relatively long, at least three to four years in general, which is always lagging behind the rapidly changing market [14]. The forward-looking vision is important for universities and colleges to grasp and predict market information and never be run passively by the nose of the market. In certain countries, the local universities or colleges have already set up some advanced majors. For example, in German, many technologies such as NC (numerical control) machining, intelligent robot, silicon controlled integration, and the application of network and commerce on the Internet, etc. are widely set up in universities. In Singapore, the setup of majors also highlights the advance, and they put forward the slogan of "to develop today's cadets and serve the future with the technology of tomorrow."

\subsection{To combine closely with school orientation, promote unbalanced and sustainable development of disciplines and specialties}

The success or failure of higher schools depends largely upon their orientation, especially in nowadays when the higher education institutions are facing unprecedented competitive situation. In fact, any university is not able to have its own characteristics and have advantages in all disciplines and specialties; instead, there are some distinct subjects and representative majors in the university. Therefore, the orientation of a school's discipline must have its own characteristics. That is to say, only by positioning accurately can we make a distinctive feature, so we should not strive for grandiose projects during the adjustment [15]. Accordingly, the institutions should further optimize, based on their own conditions and comparative advantages, the allocation of resources, and concentrate human and material resources to set the specialties and subjects that can meet the needs of local developments and are recognized by the society. Through the implementation of the key breakthrough strategy, we should construct a number of brand featured specialties, highlight the advantages of schools, and promote unbalanced and sustainable development of disciplines and specialties [16]. Meanwhile, in the implementation of unbalanced development, we must maintain the sustainable development of discipline and specialty. It is necessary to effectively configure and use educational resources to build a good professional group and make the related disciplines complement and support each other. At the same time, it is also necessary to strengthen the construction of academic group and teacher team, especially the training, selecting and stabilizing of masters and backbone talents. Only with the support of excellent masters and scholars can the majors and subjects develop in the long run.

\subsection{To improve the review system to ensure the scientificity and feasibility of specialty setting}

As a policy and academic project, the setting of majors should be taken by governments as a basic construction project related to the overall situation of higher education. Specifically, the governments should set up a dedicated review committee composed of leaders of universities and government departments (including economic, planning, personnel, education, etc.), experts and representatives of the employment department. At the same time, we must strictly work out the procedures of application and review, and strictly evaluate the necessity and feasibility of setting up new specialties [17]. That's to say, we must avoid blindness and narrow vision; instead, we must set up new specialties by considering both current needs and future trends, and take the teachers, equipment and place, etc. into consideration. Even for those majors in need of a large number of professionals, we also must avoid blindly following the wind to extremely set them up. 


\section{Acknowledgements}

Authors are grateful to the Brand Major Construction Project of University in Jiangsu (PPZY2015B103); Teaching Reform Project of Jiangsu (2017JSJG047); Project of Evaluation Committee of Higher Education Society in Jiangsu (Pgwyh07101); Teaching Reform Project of Nanjing University of Finance and Economics (JGZ1805).

\section{References}

[1] Qiu, J. P., Dong, K. \& Lee, X. T., Analysis of the innovation of universities in China and the evaluation of disciplines in 2013. Journal of China University of Geosciences (Social Sciences Edition), Vol. (13), 2013, pp. 60-61.

[2] Ding, X. C., A new approach to the adjustment of subject structure, China Higher Education, Vol. (13), 2007, pp. 5-6.

[3] Zhang, X. D., Study on the competitiveness of colleges and universities and the evaluation of university majors, Evaluation \& Management, 2005 (1), pp. 64-65.

[4] Bao, R., Study on problems of the specialty setting and optimization in the local undergraduate academy_-for the example of the A college, East China Normal University, 2007.

[5] Zhao, X. X., Establishment Study on the New Specialized Subjects of Universities, Hohai University, 2007.

[6] Xu, L.Y., Problems and Countermeasures of discipline structure adjustment in Colleges and Universities, Journal of Fujian Agriculture and Forestry University (Philosophy and Social Sciences), Vol. (9), 2006 (2), pp. 66-70.

[7] Dong, Y. W., Analysis of problems in the adjustment of disciplines and specialties in Chinese universities, Journal of Liaoning Teachers College (Social Sciences Edition), 2011 (1), pp.83-84.

[8] Zheng, M. Z., Lee, X. L. \& Lin, S. H. et al., Exploration of the dynamic optimization mechanism for the adjustment of professional structure, China University Teaching, 2012 (11), pp. 30-32.

[9] Du, C. P., The current situation, problems and countermeasures of specialty setting in universities in China, Hubei Social Sciences, 2011 (4), pp. 180-181.

[10] Sun, A. D., Research on the professional evaluation mechanism under the mode of professional self-regulation in colleges and universities, Heilongjiang Researches on Higher Education, 2013 (3), pp. 44-46.

[11] Zhang, J. \& Yuan, M. S., Optimizing structure: the choice of the faculty building of economics and management specialty, Journal of Shanxi University of Finance and Economics, 2002 (2), pp. 63-65.

[12] Lin, H. Q., Research on the Discipline and Specialty Structure Adjustment in Higher Educational Institutions, Xiamen University, 2006.

[13] Miao, N., Research on Structure Optimization of Undergraduate Specialties of Tianjin Local Universities, Tianjin University, 2012.

[14] Zhao, B. Q., Adjust and Improve the Specialty Establishment and Professional Structure of the Undergraduate Course of Institution of Higher Education, Hohai University, 2005.

[15] Liu, S. X., The Structure, Establishment and Management Mechanism of Undergraduate Majors in Universities, Beijing: Higher Education Press. 2009: preface, 97.

[16] Willian H. Allen., Self-Surveys by Colleges and Universities. NY: World Book Company, 2002.

[17] Robert Lenington, Managing Higher Education as Business. ORXY Press, 1996. 